\title{
Enterobius vermicularis Infection among Preschool Children: A 12-Year (2008-2019) Survey in Large Cities and Provinces of the Republic of Korea
}

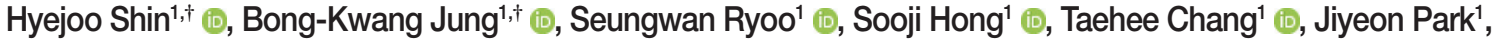 \\ Keon Hoon Lee', Jeonggyu Lee', Jae Young Park', Hoo-Gn Jeoung ${ }^{2}$, Jae Hyun Cho², Jong-Yil Chai ${ }^{1,2,3, *}$ [i] \\ 'Institute of Parasitic Diseases, ${ }^{2}$ Head Office, Korea Association of Health Promotion (KAHP), Seoul 07649, Korea; ${ }^{3}$ Department of Tropical Medicine \\ and Parasitology, Seoul National University College of Medicine, Seoul 03080, Korea
}

\begin{abstract}
A 12-year nationwide survey (2008-2019) was performed to investigate the prevalence of Enterobius vermicularis infection among preschool children in Seoul, 4 large cites (Busan, Incheon, Daegu, and Ulsan), and 9 provinces (grouped into 5 localities) in the Republic of Korea (=Korea). The survey was carried out once a year by 16 regional offices of the Korea Association of Health Promotion. The cello-tape perianal swab method (1 smear per child) was applied to detect eggs of $E$. vermicularis and other helminths. According to the results, the egg positive rate of $E$. vermicularis infection in 2008-2009 was 1.8-2.0\%, but it decreased gradually to $0.6 \%$ in $2019(P<0.05)$. The prevalence was significantly higher in boys $(0.7-5.0 \%$, mean $1.8 \%)$ than in girls $(0.5-2.8 \%$, mean $1.3 \%)(P<0.05)$. The 2 most southern localities, Jejudo (Province) and Jeolla-do (inclusive of Jeollabuk-do and Jeollanam-do) and a mid-western province, Gyeonggi-do, revealed higher prevalences, whereas Seoul and Gangwon-do showed lower prevalences. The results indicate that a lowgrade prevalence of $E$. vermicularis infection (less than $4 \%$ ) has been maintained for the recent 12 years among preschool children in Korea. Continuous monitoring of enterobiasis in the child age group is necessary in Korea.
\end{abstract}

Key words: Enterobius vermicularis, preschool children, prevalence, Korea

Enterobius vermicularis is the most common intestinal nematode worldwide infecting predominantly the children age group (5-14 years) [1,2]. E. vermicularis infection occurs by ingesting the eggs of infectious stage through contact with contaminated objects or air transmission [1,3]. Enterobiasis is generally asymptomatic but can cause anal pruritus, discomfort, insomnia, or anxiety especially in young children [4]. Although it is not considered a serious illness, it can sometimes cause serious morbidity such as appendicitis and perianal dermatitis [2]. The infection is diagnosed by microscopic examinations of eggs using the cello-tape perianal swab method [5]. The presence of eggs in perianal swabs does not necessarily mean an actual adult pinworm infection in the intestinal tract [6]. However, the egg positive rate in perianal swabs can be used to estimate the prevalence and endemicity of E. vermicularis infection in a community $[5,6]$.

\footnotetext{
- Received 2 August 2021, revised 3 August 2021, accepted 3 August 2021.

*Corresponding author (cjy@snu.ac.kr)

${ }^{\dagger}$ These authors contributed equally to this article.

(C) 2021, Korean Society for Parasitology and Tropical Medicine

This is an Open Access article distributed under the terms of the Creative Commons

Attribution Non-Commercial License (https://creativecommons.org/licenses/by-nc/4.0) which permits unrestricted non-commercial use, distribution, and reproduction in any

medium, provided the original work is properly cited.
}

For treatment and control of E. vermicularis infection, it is recommended to take albendazole $400 \mathrm{mg}$ or pyrantel pamoate $10 \mathrm{mg} / \mathrm{kg}$ in a single dose at 20-day interval at least 3 times [6]. However, it is quite difficult to manage and control the infection because of frequent and rapid reinfection and incomplete anthelmintic efficacy [2]. For this reason, it is recommended that all members of the family and classmate should be medicated at the same time. It is also important to keep the body clean and improve the environment through washing or disinfection of bedding and underwear [6].

In the Republic of Korea ( = Korea), surveys of E. vermicularis infection have been continuously conducted, and it has been shown that its prevalence is decreasing gradually over time [1$4,7-26]$. However, most of the previous surveys were conducted under limited conditions, i.e., in local regions and targeting specific group during a short period of time [1-4,7-26]. Thus, it is insufficient to understand the nationwide status of pinworm infection. In this study, we performed a 12-year nationwide survey to investigate the status of $E$. vermicularis infection among preschool children in Seoul, 4 large cities, and 9 provinces in Korea.

The survey was conducted once a year using the cello-tape 
perianal swab method during 2008-2019 targeting preschool children (aged 1-6) selected by 16 regional branches of the Korea Association of Health Promotion (KAHP). The total number of subjected preschool children during the 12 years was 638,354 . The participants were randomly selected from children attending preschools (1-234 preschools each year in each regional branch) under permissions of parents, guardians, and/or director of the preschools which are located in Seoul, 4 large cities (Busan, Daegu, Incheon, and Ulsan), and 9 provinces (grouped into 5, namely, Gyeonggi-do, Gangwondo, Chungcheongbuk-do, Chungcheongnam-do, Jeollabukdo, Jeollanam-do, Gyeongsangbuk-do, and Gyeongsangnamdo). The study protocol was approved by the Ethics Committee for Health Research, the Korea Association of Health Promotion (IRB no. 130750-202009-HR-020). The perianal swab samples were prepared by the parent according to the instruc- tions provided by the survey staff and collected from the parent or the guardian. The samples were transported to the laboratories of 16 branches of the Korea Association of Health Promotion (KAHP) and examined using a light microscope. The egg positive children were prescribed with albendazole $400 \mathrm{mg}$ in a single dose 3 times at 20-day intervals. All statistical analyses were conducted using the Excel program (Microsoft, Redmond, Washington, USA), and $P$ values of $<0.05$ were considered statistically significant.

According to the results, the egg positive rate of E. vermicularis decreased gradually within the period of investigation from $1.8 \%$ in 2008 and $2.0 \%$ in 2009 to $0.6 \%$ in 2019 (Table 1; Fig. 1A) $(P<0.05)$. The egg positive rate was significantly higher in boys $(0.7-5.0 \%$, mean $1.8 \%)$ than in girls $(0.5-2.8 \%$, mean $1.3 \%)$ at any time except in 2017 (Fig. 1B) $(P<0.05)$. The mean egg positive rate of $E$. vermicularis according to geo-
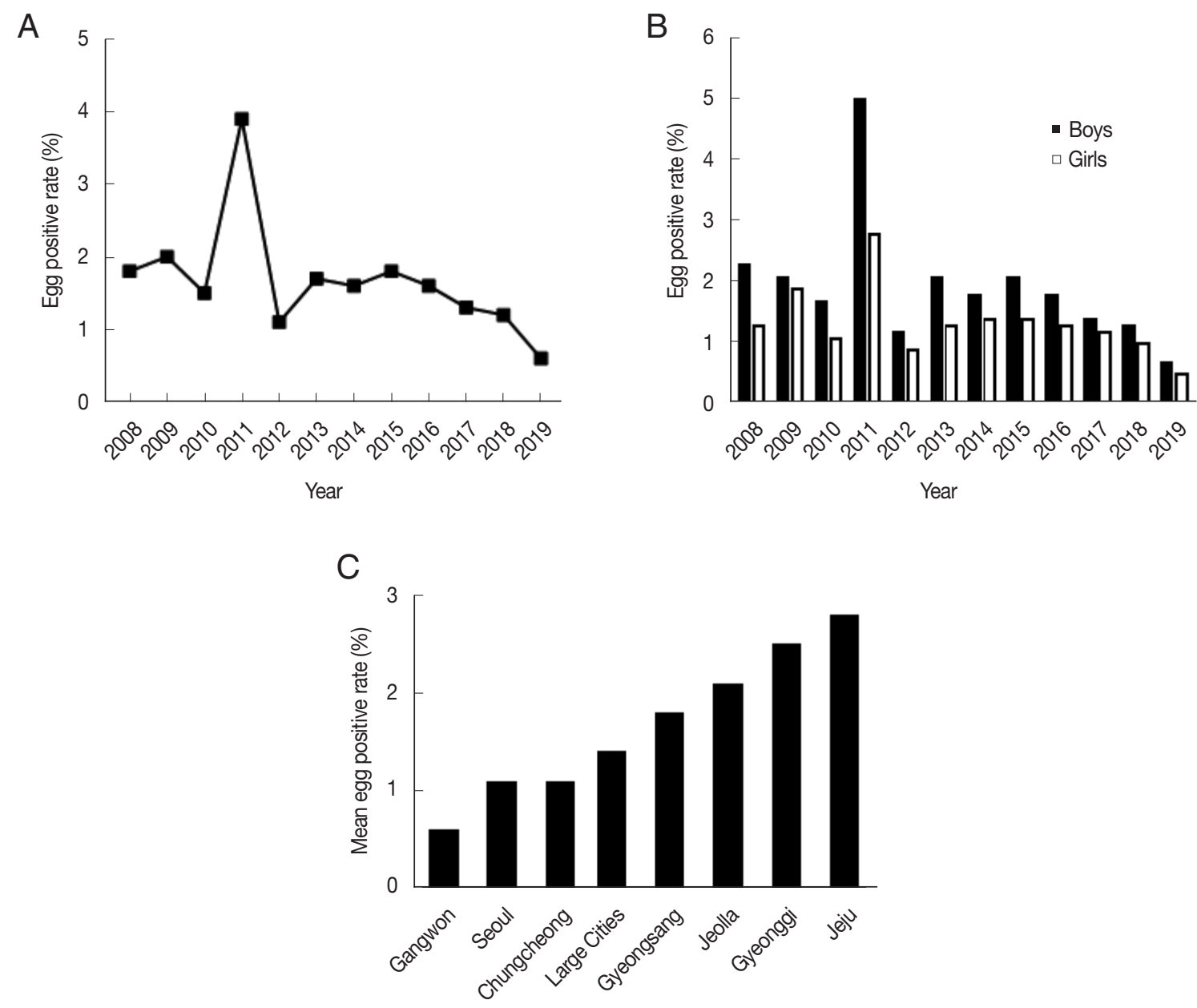

Fig. 1. The egg positive rate of Enterobius vermicularis among preschool children in various localities of the Republic of Korea, during 2008-2019 by year (A), sex (B), and geographical regions (C). 
Table 1. Yearly prevalence of Enterobius vermicularis infection among preschool children in various localities of the Republic of Korea (2008-2019)

\begin{tabular}{|c|c|c|c|c|c|c|}
\hline \multirow{2}{*}{ Survey area } & \multicolumn{6}{|c|}{ No. egg positive / No. examined (\%) } \\
\hline & 2008 & 2009 & 2010 & 2011 & 2012 & 2013 \\
\hline Seoul & $55 / 2,545(2.2)$ & $23 / 3,128(0.7)$ & 8/222 (3.6) & $7 / 273(2.6)$ & $43 / 2,676(1.6)$ & $26 / 1,527(1.7)$ \\
\hline Large cities $^{a}$ & $342 / 25,200(1.4)$ & $402 / 17,610(2.3)$ & $140 / 13,223(1.1)$ & 28/427 (6.6) & $56 / 7,977(0.7)$ & $56 / 2,937(1.9)$ \\
\hline Gyeonggi & - & - & - & $1 / 110(0.9)$ & $38 / 2,574(1.5)$ & $203 / 4,453(4.6)$ \\
\hline Gangwon & $41 / 1,890(2.2)$ & $27 / 6,635(0.4)$ & $213 / 20,866(1.0)$ & $2 / 100(2.0)$ & $101 / 20,136(0.5)$ & $77 / 16,339(0.5)$ \\
\hline Chungcheong & $169 / 15,209(1.1)$ & $211 / 16,617(1.3)$ & $45 / 4,174(1.1)$ & 6/201 (3.0) & $33 / 4,246(0.8)$ & $37 / 3,061(1.2)$ \\
\hline Jeolla & $120 / 4,571(2.6)$ & $453 / 26,107(1.7)$ & $178 / 6,674(2.7)$ & $15 / 209(7.2)$ & 140/5,339 (2.6) & $22 / 813(2.7)$ \\
\hline Gyeongsang & $430 / 16,949(2.5)$ & $292 / 14,368(2.0)$ & $46 / 2,339(2.0)$ & $5 / 200(2.5)$ & $116 / 7,934(1.5)$ & 205/15,032 (1.4) \\
\hline Jeju & $339 / 15,043(2.3)$ & $859 / 29,145(2.9)$ & $91 / 2,213(4.1)$ & 0/106 (0) & 22/483 (4.6) & $383 / 14,504(2.6)$ \\
\hline Total & 1,496/81,407 (1.8) & $2,267 / 113,610(2.0)$ & $721 / 49,711(1.5)$ & 64/1,626 (3.9) & $549 / 51,365(1.1)$ & 1,009/58,666 (1.7) \\
\hline \multirow{2}{*}{ Survey area } & \multicolumn{6}{|c|}{ No. egg positive / No. examined (\%) } \\
\hline & 2014 & 2015 & 2016 & 2017 & 2018 & 2019 \\
\hline Seoul & $30 / 1,713(1.8)$ & $30 / 2,135(1.4)$ & 37/2,381 (1.6) & 28/2,887 (1.0) & $13 / 1,880(0.7)$ & $39 / 10,765(0.4)$ \\
\hline Large cities $^{\mathrm{a}}$ & $9 / 1,275(0.7)$ & 8/846 (0.9) & $7 / 1,224(0.6)$ & $3 / 279(1.1)$ & 13/957 (1.4) & $19 / 3,980(0.5)$ \\
\hline Gyeonggi & 120/3,318 (3.6) & $71 / 2,667(2.7)$ & $56 / 2,216(2.5)$ & $13 / 2,446(0.5)$ & $12 / 1,470(0.8)$ & $9 / 1,311(0.7)$ \\
\hline Gangwon & $87 / 17,785(0.5)$ & $83 / 18,356(0.5)$ & 152/18,024 (0.8) & $101 / 16,769(0.6)$ & $84 / 16,043(0.5)$ & $37 / 15,035(0.2)$ \\
\hline Chungcheong & $56 / 3,793(1.5)$ & $9 / 2,211(0.4)$ & $1 / 1,214(0.1)$ & $41 / 2,153(1.9)$ & $1 / 556(0.2)$ & 3/1,093 (0.3) \\
\hline Jeolla & $23 / 1,518(1.5)$ & $4 / 428(0.9)$ & $16 / 836(1.9)$ & 79/2,213 (3.6) & $38 / 1,394(2.7)$ & $38 / 2,537(1.5)$ \\
\hline Gyeongsang & 236/15,903 (1.5) & 297/16,720 (1.8) & $245 / 12,119(2.0)$ & 204/10,397 (2.0) & 136/7,922 (1.7) & $21 / 2,188(1.0)$ \\
\hline Jeju & $388 / 12,482(3.1)$ & $477 / 11,774(4.1)$ & $272 / 12,247(2.2)$ & 79/4,895 (1.6) & $105 / 4,644$ (2.3) & $95 / 4,970(1.9)$ \\
\hline Total & $949 / 57,787$ (1.6) & $979 / 55,137(1.8)$ & 786/50,261 (1.6) & $548 / 42,039(1.3)$ & 402/34,866 (1.2) & $261 / 41,879(0.6)$ \\
\hline
\end{tabular}

aLarge cities included Busan, Daegu, Incheon, and Ulsan.

graphical regions during the 12 years was highest in Jeju-do, followed by Gyeonggi-do and Jeolla-do (including Jeollabukdo and Jeollanam-do) and lowest in Gangwon-do, Seoul, and Chungcheong-do (Fig. 1C).

Enterobiasis is the most common human parasitic disease worldwide, including developed and developing countries [5,6,27-29]. In Korea, the survey of the prevalence of E. vermicularis has been continuously performed in most cases targeting preschool and primary school children in various regions [14,7-26] (Table 2). According to the reports, the prevalence of $E$. vermicularis has been decreasing over time in Korea. The prevalence in 2019 was $0.6 \%$, considerably lower than other countries. Even in developed countries, the prevalence of E. vermicularis infection was quite high [27-29]. For example, in Berlin, Germany, the prevalence of E. vermicularis was $17.4 \%$ from 2007 to 2017 [27]. In the Sivas region of Turkey, the prevalence of E. vermicularis was $17.0 \%(365 / 3,569)$ co-infected with other parasites [28]. In northeastern Poland, the prevalence of $E$. vermicularis was 10.1\% between 2013 and 2015 [29].

In our study, the prevalence of $E$. vermicularis infection tended to decrease over the surveyed period from 2008 to 2019. One of the reasons for the decrease seems to be the continued hygiene education and preventive chemotherapy. In fact, Kim and $\mathrm{Yu}$ [3] reported that it was sharply reduced in the experimental group trained for preventive education about E. vermicularis infection than in the control group after 3 months of treatment. In addition, the prevalence of $E$. vermicularis was relatively lower in orphanage children than in preschool and primary school children, because the orphanage children were regularly educated about personal healthcare and infectious diseases and received medication with anthelmintics [26]. According to Kim et al. [23], parent's knowledge about enterobiasis was correlated with E. vermicularis infection of their children. For this reason, it was recommended that children and their parents be consistently provided with health education for their knowledge and prevention of enterobiasis $[3,23]$. The second reason infers from the decrease in the number of students in each class and preschool followed by the decrease in the frequency of contact and transmission rate. Actually, the average number of children per class of preschools reported by the Korean Educational Statistics Service was 26.3 in 2000, 21.0 in 2010, and 17.0 in 2019 [30]. Therefore, it is considered that the possibility of E. vermicularis infection would be increased proportionally to the number of students in a class. 
Table 2. Summary of previous surveys on the prevalence of Enterobius vermicularis infection among children or general people in Korea

\begin{tabular}{|c|c|c|c|c|}
\hline Year & Area & Target & Prevalence (\%) & Reference \\
\hline 1976 & North of Seoul & Primary school children (aged 8-9) & $73 / 107$ (68.2) & Chai et al. [7] \\
\hline 1983 & Daegu, Gyeongsangbuk-do & Residents (all age) & $118 / 1,697(7.0)$ & Joo [8] \\
\hline 1983 & Yeongyang-gun, Gyeongsangbuk-do & $\begin{array}{l}\text { Preschool children and primary } \\
\text { school children }\end{array}$ & $1,428 / 2,227(64.1)$ & Ho and Park [9] \\
\hline 1985 & $\begin{array}{l}\text { Cheongyang-gun, Chungchongnam-do; } \\
\text { Wando-gun, Jeollanam-do; Incheon }\end{array}$ & Primary school children (grade 1-6) & $316 / 860(36.7)$ & Im et al. [10] \\
\hline 1986-1988 & $\begin{array}{l}\text { Dobong-gu, Seoul; Uijeongbu and Yangju, } \\
\text { Gyeonggi-do }\end{array}$ & Primary school children (grade 1-6) & $345 / 2,156(16.0)$ & Ryang [11] \\
\hline 1987 & $\begin{array}{l}\text { Jongno-gu and Nanjido Seoul; Okku-gun, } \\
\text { Jeollabuk-do }\end{array}$ & Primary school children (aged 6-11) & $217 / 1,336(16.2)$ & Choi et al. [12] \\
\hline 1991 & Wonju, Gangwon-do & $\begin{array}{l}\text { Preschool and primary school } \\
\text { children (aged 4-12) }\end{array}$ & 251/1,262 (19.9) & Kim et al. [13] \\
\hline 1994-1995 & Chunchon, Gangwon-do & Primary school children & 138/789 (17.5) & Yang et al. [14] \\
\hline 1997 & Chorwon-gun, Gangwon-do & Handicapped people (aged 1-59) & $34 / 165(20.6)$ & Lee et al. [15] \\
\hline 1998 & Tangjin-gun, Chungcheongnam-do & $\begin{array}{l}\text { Preschool and primary school } \\
\text { children (grade 1-5) }\end{array}$ & 28/189 (14.8) & Lee et al. [16] \\
\hline 1999 & Chunchon, Gangwon-do & Preschool children & $434 / 4,711(9.2)$ & Yoon et al. [17] \\
\hline 1999 & Seongbuk-gu, Seoul & Preschool children (aged 2-7) & $113 / 1,191(9.5)$ & Song et al. [2] \\
\hline 2000 & Hamyang-gun, Gyeongsangnam-do & Primary school children (grade 1-6) & 88/654 (13.4) & Kim et al. [18] \\
\hline 2000 & $\begin{array}{l}\text { Gyeonggi-do, Incheon, Chungcheongnam-do, } \\
\text { Jeollabuk-do, Jeollanam-do, Gyeongsangnam-do, } \\
\text { Busan, Jeju-do }\end{array}$ & $\begin{array}{l}\text { Preschool and primary children } \\
\text { school (aged 3-10) }\end{array}$ & $307 / 1,661(18.5)$ & Park et al. [19] \\
\hline 2001 & Goseong-gun and Wonju, Gangwon-do & Primary school children (grade 1-6) & 39/398 (9.8) & Lee et al. [20] \\
\hline 2002 & Geoje Island, Gyeongsangnam-do & $\begin{array}{l}\text { Preschool and primary school chil- } \\
\text { dren (grade 1-6) }\end{array}$ & $74 / 754(9.8)$ & Kim et al. [21] \\
\hline $2004-2005$ & Cheongju, Chungcheongbuk-do & Preschool children (aged 3-7) & $119 / 1,512(7.9)$ & Kang et al. [1] \\
\hline 2008 & $\begin{array}{l}\text { Chuncheon and Inje-gun, Gangwon-do and Paju, } \\
\text { Gyeonggi-do }\end{array}$ & Preschool children (aged 1-7) & $285 / 7,048(4.0)$ & Hong et al. [4] \\
\hline 2008-2009 & Muan-gun, Jeollanam-do & Preschool children (aged 1-7) & $102 / 2,347(4.3)$ & Hong et al. [22] \\
\hline $2010^{a}$ & Busan, Gyeongsangnam-do & Preschool children (aged 1-7) & $179 / 1,674(10.7)$ & Kim et al. [23] \\
\hline $2011^{\mathrm{a}}$ & Gimhae, Gyeongsangnam-do & Preschool children (under aged 7) & $729 / 6,921(10.5)$ & Lee et al. [24] \\
\hline $2011^{a}$ & Southeast area of Korea & Preschool children & $205 / 3,422(6.0)$ & Kim et al. [25] \\
\hline $2012-2013$ & Industrial city, urban, and suburban areas & Primary school children (aged 7-9) & $163 / 3,840(4.2)$ & Kim and Yu [3] \\
\hline 2014 & Busan and Ulsan, Gyeongsangnam-do & Orphanage children (aged 4-13) & $1 / 117(0.85)$ & Kim et al. [26] \\
\hline
\end{tabular}

${ }^{\text {aReported year. }}$

In our study, the egg positive rate in 2011 was exceptionally high compared to other years (Fig. 1A). Two factors were suggested to be the reasons. One was the high prevalence in large cities (6.6\%) and Jeolla-do (including Jeollabuk-do and Jeollanam-do) (7.2\%) compared to lower prevalences in other areas (0-3.0\%). The other was the much smaller number of examinees in 2011 (1,626 children) compared with other years (34,866113,610 children each year). We consider that there may have an outbreak of E. vermicularis infection at that time in a few preschools subjected in this study. However, thereafter, sudden rising of the prevalence was not seen throughout the survey period.

In previous papers, the prevalence of $E$. vermicularis infection was higher in girls than in boys by 1980s, but the pattern of pinworm infection changed since the 1990s in Korea [15,17, 19-21,23-25]. Our study showed a significantly higher prevalence among boys than in girls, except in $2017(P<0.05)$ (Fig. 1 ). The precise reason why boys are more highly infected with E. vermicularis than girls is unknown. However, it is considered that inadequate personal hygiene, particularly among boys, could be a risk factor for $E$. vermicularis infection [19].

Our study has a few strong points and a few weak points. One of the strong points is the large subjected population, from around 35,000 to 114,000 subjects each year except in 2011, totaling 638,354 children during the total 12 years. Another strong point is that our study covered nationwide locali- 
ties, including Seoul, 4 large cities, and 9 provinces, thus, it was fairly good to see the national trend of $E$. vermicularis prevalence among preschool children. One of the weak points is that our study was not based on strictly randomized selection of participants in each branch of the Korea Association of Health Promotion. Another weak point is that the cello-tape perianal swabs were prepared by the parents of children, not by experienced technologists.

In conclusion, the prevalence of E. vermicularis seems to be decreasing in Korea when compared with previous results, but a low-grade infection is still maintained. Therefore, monitoring and control programs of enterobiasis should be implemented consistently in preschools in Korea. In addition, it is necessary to provide health education on enterobiasis against children as well as their parents.

\section{ACKNOWLEDGMENTS}

We would like to thank all of the preschool children participated in this study and also their parents, guardians, and directors of preschools who kindly consented to this study. We are grateful to the staff of 16 regional offices of the Korea Association of Health Promotion who helped in collection and microscopic examinations of the cello-tape perianal swab smears.

\section{CONFLICT OF INTEREST}

We have no conflict of interest related to this study.

\section{REFERENCES}

1. Kang S, Jeon HK, Eom KS, Park JK. Egg positive rate of Enterobius vermicularis among preschool children in Cheongju, Chungcheongbuk-do, Korea. Korean J Parasitol 2006; 44: 247-249. https://doi.org/10.3347/kjp.2006.44.3.247

2. Song HJ, Cho CH, Kim JS, Choi MH, Hong ST. Prevalence and risk factors for enterobiasis among preschool children in a metropolitan city in Korea. Parasitol Res 2003; 91: 46-50. https:// doi.org/10.1007/s00436-003-0836-3

3. Kim DH, Yu HS. Effect of a one-off educational session about enterobiasis on knowledge, preventative practices, and infection rate among schoolchildren in South Korea. PLoS One 2014; 9: e112149. https://doi.org/10.1371/journal.pone.0112149

4. Hong SH, Lee SE, Jeong YI, Lee WJ, Cho SH. Comparison of egg positive rates of Enterobius vermicularis among preschool children in three Korean localities. Korean J Parasitol 2011; 49: 441-443. https://doi.org/10.3347/kjp.2011.49.4.441

5. Chai JY, Yang SK, Kim J, Choi SL, Song GY, Jung BK, Kim MJ, Cho J, Kim DG, Sohn WM, Jeoung HG, Cho S, Park JB, Hong S, Htoon TT, Tin HH. High Prevalence of Enterobius vermicularis infection among schoolchildren in three townships around Yangon, Myanmar. Korean J Parasitol 2015; 53: 771-775. https://doi. org/10.3347/kjp.2015.53.6.771

6. Chai JY, Hong ST, Choi MH, Shin EH, Bae YM, Hong SJ, Sohn WM, Yu JR, Kho WG, Seo M, Park YK, Han ET. Clinical Parasitology. Seoul, Korea. SNU Press. 2015, pp 246-251 (in Korean).

7. Chai JY, Cho SY, Kang SY, Seo BS. Frequency distribution of Enterobius vermicularis in a highly endemic population. Korean J Parasitol 1976; 14: 103-108. https://doi.org/10.3347/kjp.1976.14.2.103

8. Joo CY. Recent patterns of intestinal helminth infections among the residents in Taegu city, Korea. Korean J Parasitol 1984; 22: 109-115. https://doi.org/10.3347/kjp.1984.22.1.109

9. Ho S, Park CB. Status of Enterobius vermicularis infection in primary school children, Yongyang-gun, Kyongbuk province. Korean J Parasitol 1984; 22: 138-140 (in Korean). https://doi.org/10. 3347/kjp.1984.22.1.138

10. Im KI, Ryu JS, Yong TS, Lee JH, Kim TU. The egg detection rates of Enterobius vermicularis among school children in the various regions. Korean J Parasitol 1986; 24: 205-208 (in Korean). https:// doi.org/10.3347/kjp.1986.24.2.205

11. Ryang YS. Recent patterns of Enterobius vermicularis infection in some school children, Korea. Korean J Parasitol 1988; 26: 215220 (in Korean). https://doi.org/10.3347/kjp.1988.26.3.215

12. Choi WY, Yoo JE, Nam HW, Kim JH, Lee UH. Egg detection rates of Enterobius vermicularis in children. Korean J Parasitol 1987; 25: 181-184 (in Korean). https://doi.org/10.3347/kjp.1987.25.2.181

13. Kim JS, Lee HY, Ahn YK. Prevalence of Enterobius vermicularis infection and preventive effects of mass treatment among children in rural and urban areas, and children in orphanages. Korean J Parasitol 1991; 29: 235-243 (in Korean). https://doi.org/10.3347/kjp. 1991.29.3.235

14. Yang YS, Kim SW, Jung SH, Huh S, Lee JH. Chemotherapeutic trial to control enterobiasis in schoolchildren. Korean J Parasitol 1997; 35: 265-269. https://doi.org/10.3347/kjp.1997.35.4.265

15. Lee J, Park GM, Lee DH, Park SJ, Yong TS. Intestinal parasite infections at an institution for the handicapped in Korea. Korean J Parasitol 2000; 38: 179-181. https://doi.org/10.3347/kjp.2000.38.3.179

16. Lee KJ, Lee IY, Im KI. Enterobius vermicularis egg positive rate in a primary school in Chungchongnam-do (province) in Korea. Korean J Parasitol 2000; 38: 177-178. https://doi.org/10.3347/kjp. 2000.38.3.177

17. Yoon HJ, Choi YJ, Lee SU, Park HY, Huh S, Yang YS. Enterobius vermicularis egg positive rate of pre-school children in Chunchon, Korea (1999). Korean J Parasitol 2000; 38: 279-281. https:// doi.org/10.3347/kjp.2000.38.4.279

18. Kim BJ, Yeon JW, Ock MS. Infection rates of Enterobius vermicularis and Clonorchis sinensis of primary school children in Hamyanggun, Gyeongsangnam-do (province), Korea. Korean J Parasitol 2001; 39: 323-325. https://doi.org/10.3347/kjp.2001.39.4.323 
19. Park JH, Han ET, Kim WH, Shin EH, Guk SM, Kim JL, Chai JY. A survey of Enterobius vermicularis infection among children on western and southern coastal islands of the republic of Korea. Korean J Parasitol 2005; 43: 129-134. https://doi.org/10.3347/kjp. 2005.43.4.129

20. Lee KJ, Ahn YK, Ryang YS. Enterobius vermicularis egg positive rates in primary school children in Gangwon-do (province), Korea. Korean J Parasitol 2001; 39: 327-328. https://doi.org/10.3347/ kjp.2001.39.4.327

21. Kim BJ, Lee BY, Chung HK, Lee YS, Lee KH, Chung HJ, Ock MS. Egg positive rate of Enterobius vermicularis of primary school children in Geoje island. Korean J Parasitol 2003; 41: 75-77. https:// doi.org/10.3347/kjp.2003.41.1.75

22. Hong SH, Jeong YI, Lee JH, Cho SH, Lee WJ, Lee SE. Prevalence of Enterobius vermicularis among preschool children in Muangun, Jeollanam-do, Korea. Korean J Parasitol 2012; 50: 259-262. https://doi.org/10.3347/kjp.2012.50.3.259

23. Kim DH, Son HM, Kim JY, Cho MK, Park MK, Kang SY, Kim BY, Yu HS. Parents' knowledge about enterobiasis might be one of the most important risk factors for enterobiasis in children. Korean J Parasitol 2010; 48: 121-126. https://doi.org/10.3347/kjp. 2010.48.2.121

24. Lee SE, Lee JH, Ju JW, Lee WJ, Cho SH. Prevalence of Enterobius vermicularis among preschool children in Gimhae-si, Gyeongsangnam-do, Korea. Korean J Parasitol 2011; 49: 183-185. https://doi. org/10.3347/kjp.2011.49.2.183
25. Kim DH, Cho MK, Park MK, Kang SA, Kim BY, Park SK, Yu HS. Environmental factors related to enterobiasis in a southeast region of Korea. Korean J Parasitol 2013; 51: 139-142. https://doi. org/10.3347/kjp.2013.51.1.139

26. Kim DH, Son HM, Lee SH, Park MK, Kang SA, Park SK, Choi JH, Park JH, Yu HS. Negligible egg positive rate of Enterobius vermicularis and no detection of head lice among orphanage children in Busan and Ulsan, Korea (2014). Korean J Parasitol 2015; 53 497-499. https://doi.org/10.3347/kjp.2015.53.4.497

27. Friesen J, Bergmann C, Neuber R, Fuhrmann J, Wenzel T, Durst A, Müller M, Ignatius R. Detection of Enterobius vermicularis in greater Berlin, 2007-2017: Seasonality and increased frequency of detection. Eur J Clin Microbiol Infect Dis 2019; 38: 719-723. https://doi.org/10.1007/s10096-019-03495-1

28. Celiksoz A, Acioz M, Degerli S, Oztop AY, Alim A. Effects of enterobiasis on primary school children. Afr J Microbiol Res 2010; 4: 634-639. https://doi.org/10.5897/AJMR.9000268

29. Kubiak K, Dzika E, Paukszto L. Enterobiasis epidemiology and molecular characterization of Enterobius vermicularis in healthy children in north-eastern Poland. Helminthologia 2017; 54: 284-291. https://doi.org/10.1515/helm-2017-0042

30. Korean Educational Statistics Service. Number of students per class by year [Internet]; Avialable from: https://kess.kedi.re.kr/ mobile/kessTheme/zipyoDetail?menuCd=030201\&cd=929\&sur vSeq $=0000$ \&itemCode $=\&$ menuId $=$ \&uppCd $1=030201$ 